Article

\title{
Privacy and Digital Data of Children with Disabilities: Scenes from Social Media Sharenting
}

\author{
Gerard Goggin ${ }^{1, *}$ and Katie Ellis ${ }^{2}$ \\ ${ }^{1}$ Wee Kim Wee School of Information and Communication, Nanyang Technological University, 637718, Singapore; \\ E-Mail: gerard.goggin@ntu.edu.sg \\ ${ }^{2}$ Centre for Culture \& Technology, Curtin University, Perth, WA 6845, Australia. E-Mail: katie.ellis@curtin.edu.au \\ * Corresponding author
}

Submitted: 15 June 2020 | Accepted: 4 September 2020 | Published: 10 November 2020

\begin{abstract}
Children with disabilities have been an overlooked group in the debates on privacy and data management, and the emergence of discourses on responsibilization. In this article, we offer a preliminary overview, conceptualization, and reflection on children with disabilities, their experiences and perspectives in relation to privacy and data when it comes to existing and emergent digital technology. To give a sense of the issues at play, we provide a brief case study of "sharenting" on social media platform (that is, sharing by parents of images and information about their children with disabilities). We conclude with suggestions for the research and policy agenda in this important yet neglected area.
\end{abstract}

\section{Keywords}

accessibility; children with disabilities; data rights; disability rights; Internet rights; privacy

\section{Issue}

This article is part of the issue "Children's Voices on Privacy Management and Data Responsibilization" edited by Ralf De Wolf (Ghent University, Belgium) and Mariek Vanden Abeele (Tilburg University, The Netherlands).

(C) 2020 by the authors; licensee Cogitatio (Lisbon, Portugal). This article is licensed under a Creative Commons Attribution 4.0 International License (CC BY).

\section{Introduction}

Debate on privacy and data management, and the emergence of discourses such as responsibilization, has grown considerably in response to recent developments in digital technologies.

Activists, policy actors, scholars, children's allies, and others have pointed out the high stakes for children in the transforming digital environment-and argued for the importance of children's voices to be heard, listened to, and acted upon, in order for issues of privacy, data, surveillance, and so on, to be better understood and addressed (Livingstone \& Third, 2017). There has been important work on privacy and children, and an acknowledgement that this is only the 'tip of the iceberg,' as this thematic issue underscores, in relation to children's perspectives, experiences, and voices.

An especially overlooked group in this regard are children with disabilities (Ellis, Goggin, \& Kent, in press;
Jordan \& Prendella, 2019). While significant efforts have been made to bring attention to and address issues they face, and to support their participation in shaping digital technologies and policies, they remain notably under-represented in the various forums, institutions, corporate and policy arena. This situation has profound consequences, as Sonia Livingstone and Amanda Third underscore:

The persistent exclusion of children living with disability illustrates a host of challenges associated with intersectionality online as offline. Such challenges are particularly acute online because of the hitherto lack of flexibility or contingency in the regulation of digital resources and infrastructure by comparison with the nuanced possibilities for shaping social norms and opportunity structures offline. (Livingstone \& Third, 2017, p. 665) 
Hence the importance of the moves to put children on the wider agenda of disability human rights as well as disability research. Also, the significance in the past twoplus decades of children with disabilities being recognized as an important part of the burgeoning area of children's rights, especially rights in relation to digital societies (Alper \& Goggin, 2017; Livingstone \& Third, 2017).

Consider, for instance, the overlap between the rights set out in both the 1989 UN Convention on the Rights of the Child (CRC) and the 2006 UN Convention on the Rights of Persons with Disabilities (CRPD; Alper \& Goggin, 2017). The CRC was the first human rights treaty to dedicate an article to the rights of persons with disabilities (CRC, 1989, Article 23). For its part, the CRPD includes a standalone article on children with disabilities (CRPD, 2006, Article 7), the mainstreaming of children's rights via specific amendments (Schulze, 2010), and the inclusion of a number of child-specific issues such as birth registration, the right of children to family life rather than placement in institutions, and the right to play (Lansdown, 2014). The CRPD also includes a number of articles stipulating accessibility and inclusive design of digital technology, in particular-something that for the past fifteen years has been a touchstone for gauging progress on the wider global achievement of disability equality and rights.

There are a range of reasons why privacy and data in relation to digital media technologies stand to be just as or even more important for children with disabilities. Consider, for instance, the wide ranging efforts to specifically design and deploy many mobile technologies and apps to address specific requirements of a diverse range of children with disabilities; let alone the many ways in which children with disabilities access and rely upon a wide range of digital content, formats, and platforms to undertake many aspects of their daily home. Most of these technologies are underpinned by data collection and use, often gathering information from a range of inputs and interfaces (touch, voice, bodily and environment moment sensors, as well as traditional and new forms of user-generated content).

As yet we have little research that charts and theorizes these experiences and issues-let alone work by and with children with disabilities, as well as work that discusses the complex issues of voice and listening (cultural, social, and political) at play in emerging technologies, digital cultures, and platforms.

Accordingly, in this article, we offer a preliminary overview, conceptualization, and reflection on children with disabilities, their experiences and perspectives in relation to privacy and data when it comes to existing and emergent digital technology. To give a sense of the issues at play, we provide a brief case study of 'sharenting' on social media platform (that is, sharing by parents of images and information about their children with disabilities). We conclude with suggestions for the research and policy agenda in this important yet neglected area.

\section{Children with Disabilities, Privacy, and Data}

As it has been redefined in the past two decades, disability is now understood as a social, political, cultural, and rights-based matter, rather than some kind of biomedical condition or charity issue (Campbell, 2009; Goodley, Lawthom, Liddiard, \& Runswick-Cole, 2019; Shakespeare, 2018).

For example, in accounts such as the social model approach, which developed from UK activists and disability researchers from the 1970s onwards (Oliver, 2013), disability is understood as the way that society responds to the realities of living life with impairments. According to proponents of the social model, people are disabled by their environment, by oppressive social relations and situations, rather than by the diversity of impairment and disabilities, which are part of what it is to be human and live in the world. Ideas, understandings, economies, and cultures, including technological systems, remain deeply shaped by problematic attitudes and stereotypes of disability, which are the correlates of the unjust, inequitable social arrangements that, while powerfully challenged in recent years, still persist and are unconsciously and deliberately reproduced (Beckett \& Campbell, 2015). As part of this rich movement of disability activism, art, media, and research, there is now a significant, fast emerging body of work on media, technology, and disability (Alper, 2017; Ellcessor \& Kirkpatrick, 2017; Ellis, Goggin, Haller, \& Curtis, 2020; Lazar \& Stein, 2017; Roulstone, 2016).

When it comes to children with disabilities and media specifically, the picture is less clear. In disability research, there is a body of rich research on experiences and perspectives of children with disabilities across a number of areas from health to media and cultural production, including accounts in their own voices (Ajodhia-Andrew, 2016; Foley et al., 2012; Runswick-Cole, Curran, \& Liddiard, 2018). There is considerable work on inclusive research, and approaches to co-researching and collaborative research with children with disabilities (see, for instance, Liddiard et al., 2019). From the direction of children media's research (Alper, 2014) and especially recent research on Internet and digital rights of children, there are significant examples of research co-conceived and conducted with children aiming to support their independency, lived experiences, and ideas (see, for example, Benjamin-Thomas et al., 2019). As yet, however, there is little cross-over in terms of specific research on privacy and data issues and perspectives pertaining to and generated by children with disabilities. Given this gap, it is useful to return to some fundamental considerations about privacy and data, and the specific ways they unfold in relation to disability.

There is a longstanding discussion over diverse areas that affect people with disabilities (Montague, 1993). As Jasmine E. Harris puts it:

Privacy and disability have an odd relationship. States, communities, and families, sometimes forcibly, have 
hidden people with disabilities from public view and engagement. In the shadow of a history of forced isolation and as a way of managing the stigma of disability, people with disabilities have, at times, rejected their public identity as disabled. (Harris, 2020, p. 159)

Key starting points include: the complex and important fundamental issues of an individual's personal information about their disability status; what meanings and contexts of disability are in relation to privacy and data; and what kinds of control and rights people with disabilities should be accorded and be able to exercise-in relation to what kinds of technologies. As Harris encapsulates it:

While some people may explicitly deny disability identity for a host of legitimate reasons, more often, people with disabilities capable of "passing" choose to move in the world without disclosing their disability identity even when disclosure can lead to greater access to services, accommodations, or other benefits. At other times, people capable of passing who wish to disclose are discouraged and, at times, prevented from disclosing. (Harris, 2020, p. 159)

To give an example, in universities and schools across many jurisdictions, students with disabilities need to disclose their 'official' disability status, or 'register' as a student with disabilities (and be acknowledged as such) before they can receive 'accommodations.' Of course, this means that students with disabilities are registered and tracked by such educational systems - a part of a wider 'governmentality' of disability (Tremain, 2015). This also raises questions of so-called 'invisible disabilities,' not officially recognized or credited as triggering institutional responses and management. Also the question of the burden of inclusive education often rests on people with disabilities needing to declare disability status, rather than schools or universities ensuring inclusive, accessible environments, teaching, learning, and full membership of educational communities, as a matter of course (Price, 2011; Whitburn \& Plows, 2017). Information regarding someone's disability is an issue widely seen as requiring confidentiality and raising privacy issues when it comes to employment and work (Twomey, 2010).

The visibilities, roles, and meanings of disability in the public sphere have been historically complex and often closely associated with the oppressions of disablism and ableism (Hadley, 2014; larskaia-Smirnova, 2020; Schweik, 2009). In turn, disability in the private sphere has been subject to other kinds of issues and modes of regulation (Priestley \& Shah, 2011). Thus, the "privateness" and "publicness" of disability is a fraught and shifting area, along with other realignments of public and private life especially new forms of 'mediated visibility' key to constituting the public sphere now, amounting to what J. B. Thompson called a decade ago, 'mediated publicness' (Thompson, 2011, p. 56). Here the issues concerning privacy and data facing people with disabilities can be seen to flow into a larger set of issues about visibility, recognition (Maia, 2014), justice, voice (Couldry, 2010), and listening (Goggin, 2009).

This situation also may lead to some potential contradictions between advancing disability justice and rights, and older notions of disability privacy. Still we face wellfounded fears that disclosure or communication regarding disability in relation to one's self-like sexuality or gender-would be a disadvantage, and lead to potential discrimination or disadvantage. Hence Jasmine Harris argues for a more "publicity-oriented approach to disability, particularly given the success of other social movements with this strategy," rather than relying upon "privacy and nondisclosure of disability status" (Harris, 2020, p. 170). She feels a discomfort with the latter, which she sees as a well-entrenched strategy that she feels construes privacy in a way that "undermines the very values disability rights law seeks to develop: the right to live in the world" (Harris, 2020, p. 170).

This kind of typical framing of disability and privacy is a main reason why this area remains extremely underexplored. Yet such investigation and discussion is urgent, given the intense societies' reliance on digital technologies with the issues they pose for privacy and data, as well as mediated publicness. As McRae, Ellis, Kent, and Locke (2020) point out, people with disabilities have particularly important and acute experiences, affordances, and perspectives on evolving privacy and data issues associated with digital technologies, and the mixed feelings many users have:

This unease becomes acute when considering people with disability for whom technology and digital interfaces have become an essential and liberating part of the everyday. The ways in which these individuals form a node of and for a radical and reflexive engagement with privacy and consent, technology and society, and anonymity and visibility offer evocative terrain for consideration. (McRae et al., 2020, p. 423)

For instance, issues of control and consent when it comes to data have been in many ways anticipated by everyday digital life contexts of people with disabilities:

People with disability monitor the boundaries between technology, consent, and privacy. Many of the privacy concerns currently being navigated by users of social media have been consciously engaged by people with disabilities who utilize assistive technologies, participate in cutting edge medical treatments or deal regularly with the medical industry, and who manage day-to-day intrusions upon their selfhood from inquiring gazes and invasive questions about their daily lives. (McRae et al., 2020, pp. 423-424)

So the kinds of considerations and desirata in understanding the 'contextual integrity' that Helen 
Nissenbaum famously put at the centre of her influential concept of privacy (Nissenbaum, 2004, 2011) when it comes to people with disabilities. Such issues are all the more obscure and in need of discussion when it comes to children with disabilities. We will turn to this now, but very much having in mind the ethical, philosophical, and political trajectory that Harris marks out. That is, how we can understand privacy for children with disabilities that advances their rights to "live in the world," and adequately captures their valid "ways of being in the world" (Garland-Thomson, 2017, p. 133).

So, what are the kinds of privacy and data issues that are faced by children with disabilities in relation to digital technologies?

Privacy conditions, practices, and claims of children with disabilities in relation to their personal information and data certainly are strongly influenced by the shared conditions of digital infrastructures at present. These are the concerns widely raised by citizens, policymakers, and researchers alike, especially in relation to the affordances and arrangements concerning data-intensive digital platforms in recent years.

Concerns include issues related to the impact of increased commercialization, very sensitive and pervasive nature of the data these companies collect and use, and the potential consequences thereof, of children's rights to privacy and data protection, the responsibilities for companies, and the need for responsive law, regulation, and policy frameworks that take children's concerns seriously. Children with disabilities also likely face a significant impost in terms of the 'costs of connection,' and, if general critiques of disability and data are to be credited, specific and notable experiences of and subject to 'data colonialism' (Couldry \& Mejias, 2019). Such issues are most likely to be heightened in relation to children with disabilities - and this is something on which we urgently need authoritative research and baseline data.

Amidst the reflex focus on risk and responsibility, there is also the need to better understand, acknowledge, and support the everyday, innovative use of digital technologies by children with disabilities. A key social imaginary of children with disabilities and technology is the great boon, if not salvation, it can confer-as, for instance, in the way that the advent of iPads have been acclaimed as a 'revolution' in the lives of children with disabilities (Alper, 2015), supporting learning and classroom participation, as well as providing enhanced access to information, entertainment, and communication. Digital inclusion is crucial especially when it comes to children with disabilities. This is because emerging digital technologies if conceived, designed, and implemented by and with people with disabilities can properly deliver the kind of quantum leap in accessibility often promised. Also, the new kinds of exclusion that can be associated with data and digital technologiesevident in the implementation of automation, machine learning, and Al, for instance-can be best foreclosed or addressed.
To understand the various sides of digital futures alluded to here, it would be helpful if we can learn more about how children with disabilities' view, secure, and finesse their privacy rights, ownership, and control of their information and data, in the process of forging their own paths to negotiating digital life and becoming and being citizens. Here we point to the important work undertaken by Amanda Third, Philippa Collin, Sonia Livingstone, and other children digital media and rights researchers in collaboration with UNICEF and NGOs that seeks to include children with disabilities and their voices, and put these at the centre of research and policy agenda (Livingstone \& Third, 2017; Third, Bellerose, Oliveira, Lala, \& Theakstone, 2017; Third \& Collin, 2016).

Having sketched this larger backdrop and agenda, we offer a brief case study of privacy and data issues raised from a relatively common and recognizable scenario: the sharing of information on children with disabilities by their parents via social media platforms, so-called 'sharenting.' What this case study vividly indicates is a fundamental axis of power relations that shapes privacy and data for this ground. Namely, children with disability are rarely considered the owners of their private information. From their parents, to charity organisations to medical discourse writ large, the private lives of children with disability are considered public domain.

\section{Scenes from "Sharenting" on Social Media}

Just prior to Christmas 2015, the website The Mighty, at that time 'disability' branded and very widely promoted in this way, published an article entitled "Introducing: Meltdown Bingo" (the article is longer accessible, see Griffo, 2015). The squares in the bingo card in question included sensory and behavioural reactions a person with autism might experience while having a "meltdown." The suggestion was that parents could "play bingo" while their child has a meltdown brought on by the sensory overload of the festive season. The article described the way in which a mother referenced the Bingo card meme to draw attention to the challenging aspects of Christmas shopping and other activities for her family and in particular her eight-year-old son who has autism.

The mother and author of the piece also identified as being on the spectrum. However, the article was widely condemned by both disability and neurodiversity communities as being exploitative and damaging (Gibson, 2016) the dedicated \#cripthemighty hashtag emerged in response, drawing on critical approaches to disability and autism (see Sinclair, 1993/2012). A critical approach to autism "[explores] power relationships that construct autism; [enables] narratives that challenge dominant negative medical autism discourses and [creates] theoretical and methodological approaches that are emancipatory and value the highly individual nature of autism and its nascent culture" (Woods, Milton, Arnold, \& Graby, 2018, p. 975; see also Yergeau, 2018). 
The Meltdown Bingo article is one example of a power relationship that constructs autism. It was interpreted as an example of both a large media organisation exploiting a disabled child for page views and a massive parental violation of privacy. Would the eight-year-old feel he was being made fun of? Would he be subject to bullying at school? Why would a disability branded website publish an article that contributed to damaging representations of disability? The representation took a psychic toll on adults with autism who described being ridiculed their whole lives. As a result, The Mighty became embroiled in an online war with activists that was picked up by the mainstream media. Many adult bloggers with autism were consequently excommunicated from The Mighty vast online community, others left in protest, and the site underwent a complete rebranding.

The Mighty now describes itself as a "digital health platform." This rebranding from a disability focused site to one concerned with health is not a subtle change, it was a recognition that the organisation had never moved beyond a biomedical focus in the first place. Perhaps this was because it foregrounds the perspective of parents of children with disability over the voices of people with disabilities (see Logsdon-Breakstone, 2015).

Drawing on the theory of communication privacy management, we can see these various actors as engaged in a negotiation of privacy limits generating considerable boundary turbulence. Since this controversy, the privacy turbulence between disabled adults and socalled special needs parents has intensified across other online practices from sharenting to microcelebrity, family influencers, and calibrated amateurism (for a discussion of the practices see Abidin, 2017, 2018). Sharenting and communities of practice are of particular concern and our focus in this article.

Sharenting, a portmanteau of the words parent and sharing, refers to online practices of parents who broadcast details and/or images of their children's lives online, usually on social media. While sharenting is often criticised, some positive aspects are recognized. These often focus on the formation of communities of interest whereby parents form communities around particular experiences and embark on a process of learning together. Parents of children with disability can become deeply embedded in these communities.

More recently, there has been the phenomenon of so-called family influencers who post videos of their children with autism experiencing extreme emotional states (popularly called "meltdowns"). According to these families these videos amass the most views and offer a potential to monetise content (Borgos-Rodriguez, Ringland, \& Piper, 2019). However, these families emphasize that providing support and community is their real motivation. Making aspects of their lives public for the benefit of others is in stark contrast to offline studies where parents would only disclose their child's autism diagnosis if by doing so their child would benefit (Hays \& Butauski, 2018). Indeed, some studies show that parents of chil- dren with disability report less social stigma in online communities (Ammari, Morris, \& Schoenebeck, 2014).

According to Tama Leaver (in press) parents balance three points of privacy practices with and for their children in digital contexts: privacy stewardship, boundary turbulence, and intimate surveillance. In relation to instances such as the "sharenting" cases we discuss, an issue for disability lies in the ways biomedical and charity discourses of disability influence conventions surrounding this balancing and the creation of "privacy rules." The analysis is informed by a social, political, cultural, and rights-based approach to disability. This approach problematizes biomedical and charity discourses of disability. The image of the cute disabled child has long been leveraged by charity organisations trying to raise funds (Hevey, 1992; Longmore, 2005) or more recently as click bait (Young, 2012; Ellis, 2015). This image is achieving greater potency in user generated contexts and as mommy blogging moves through to microcelebrity and family influencers. Yet the parents themselves may have different motivations.

The theory of communication privacy management, advanced by Sandra Petronio posits that "people make choices about revealing or concealing based on criteria and conditions that they perceive as salient, and that individuals fundamentally believe they have a right to own or regulate their private information" (Petronio, 2002 , p. 2). The decision to reveal also depends on how this information may affect other people. Petronio (2002) identifies five criteria of privacy management: ownership, control, privacy rules, shared ownership, and boundary turbulence. While Leaver's (in press) analysis foregrounds an assumption of shared ownership as optimal, children with disability do not always have this opportunity as parents often assume full not coownership of private information.

Parents engage in a process of communication privacy management when they share information about and/or images of their children online. The issue of sharenting on social media has received significant scholarly and media attention; however, there is none from a critical disability perspective of which we are aware. In academic discussions disability is almost always conflated with health and often functions as a narrative prosthesis (see Mitchell \& Snyder, 2000) for the benefits of sharenting; whereby parents of children with disability can share their struggles online to gain support, or alternatively offer support for new parents. In effect, in this dominant view, parents assume the role as the active and important agents in the discussion, with children with disability serving as a widely accepted key site of social anxiety. The sum total of this arrangement is a reinforcement of pervasive social assumptions that "other" and stigmatize people with disability.

The oversharing of images and details of their children's lives that would have previously been considered private on social media is a common practice amongst parents. As the regulators of their children's privacy 
limits, these parents, not their children, are the ones deciding what to reveal or conceal. Academic analysis has largely focused on parental motivation rather than offering a clear definition of the practice, when it becomes problematic, and at a deeper level, what kinds of social relations are at stake in framing children with disabilities, their voices, data, and privacy (or lack thereof) in this way. Practical rather than ideological factors influencing decision making are usually the focus. For example, in a study focused on mothers, Kumar and Schoenebeck (2015) observe the development of a community of practice:

Mothers use the Internet to seek information, advice, and support. Sharing information about one's children online provides social capital benefits. Women who participate in 'mommy blogging' enjoy validation and solidarity, develop a sense of community with others, and may experience greater wellbeing and increased feelings of connectedness. (p. 1304)

Despite this and other studies' focus on mothers, fathers also seek out communities of shared interest and collective learning. In a study of new parents' use of social media, Bartholomew, Schoppe-Sullivan, Glassman, Kamp Dush, and Sullivan (2012) found that while 98\% of new mothers post images of their children for the purpose of building community on social media, $89 \%$ of fathers do likewise. Indeed, fathers are documenting and discussing their experiences of fatherhood online as part of a broader cultural shift and reconstruction of caring masculinities (Scheibling, 2020). When compared to other parents, parents of children with "special education needs" actually use the internet less in general yet report using a wider variety of devices and spend more time "seeking information on their child's health" (Zhang \& Livingstone, 2019, p. 7).

Advice and support are primary motivations for sharenting amongst this group. Similarly, from a health perspective, the creation of peer-to-peer support via online communities is recognized as "complementing existing health services" and providing emotional and practical support to other people who may face similar issues (Eysenbach, Stendal, Petrič, Amann, \& Rubinelli, 2017). Positive aspects of sharenting have been identified by scholars, especially in when it comes to analysis of the sharenting practices of parents of children with disability, as Kopecky, Szotkowski, Aznar-Díaz, and Romero-Rodríguez (2020) explain: "Sharenting can also support the cooperation of parents whose children suffer from varying degrees of physical or mental disability, allowing to share good practice (what parents have tried and what is proved), they support each other, consult, etc." (p. 1). The difficulty in this position is that it is underpinned by a biomedical approach to disability in which disability is a problem located in the individual body in need of fixing. This speaks to a broader conflict between the medical model and social models of disabil- ity that parents of children with disability must navigate. As Sonia Livingstone and Alicia Blum-Ross (2020) reflect:

Many parents we interviewed were attracted to the social model of disability for offering a language that supported their child as not being less than, along with its critical lens on "mainstream" society's inability to provide the support they and their child needed. At the same time, they drew on the "medical model" because this is the language typically employed by support services, and parents were often preoccupied with juggling appointments with medical or learning specialists in ways designed to manage or mitigate the effects of their child's disability. (p. 121)

Another compounding issue in many online communities in which sharenting is prevalent is that misinformation can be rife-for example some private Facebook groups were found to be advocating the use of bleach enemas as a cure for autism (Zadrozny, 2019). This is an extreme and life-threatening example that came to light due to the efforts of two mothers of children with disability who joined these groups and reported their activities.

In this way, parents of children with disability can likewise act as powerful allies. Returning to Livingstone and Blum-Ross' (2020) study, the use of online communication by parents of children with disability is "popular [though] not without its problems." There is a diversity of experience, some parents being unable to find community in an ocean of information and competing agendas while others report experiencing intense unwanted attention (Livingstone and Blum-Ross, 2020). For example, they profile the activities of one mother who changed her approach to blogging when one of her posts about parenting a child with autism went viral. Having approached the blog as a way to blow off steam, as she would in a social setting, when the post reached a large audience it suddenly became a privacy violation of her child's experience that she may have to answer to one day. Although blogging about her own frustrations, this mother was also representing her daughter's life and struggles. The experience raised ethical considerations about who has the right to speak and potentially being held to account by her daughter at some point in the future for speaking of her behalf (Livingstone \& Blum-Ross, 2020).

This is a recurring concern for critics of the sharenting practices of parents of children with disability:

Imagine a child who has behavior problems, learning disabilities or chronic illness. Mom or Dad understandably want to discuss these struggles and reach out for support. But those posts live on the Internet, with potential to be discovered by college admissions officers and future employers, friends and romantic prospects. A child's life story is written for him before he has a chance to tell it himself. (Kamenetz, 2019) 
Scholars and influencers identify some privacy conventions that have been established over time such as not identifying the child by name and taking photos from behind, never showing the child's face. Two important privacy conventions observed by influencer Anna Whitehouse are "ensuring no bathtime or swimming suit or naked images are used" and considering how your child would feel reading the post in 10 years' time (Whitehouse, 2018). Parents of children with disability seeking advice and community online have been accused of flouting these conventions by high profile disability activists who highlight the dangers of sharing medical or personal details (Counsel, 2019). Kumar and Schoenebeck observe that parents take on a "privacy stewardship" for their children in which they decide and enforce what is appropriate to share about their children (Kumar \& Schoenebeck, 2015). However, these parents, influenced by a medical approach to disability can make bad decisions. In addition, for some children with disability this stewardship may never end. The privacy of disabled children is a concern for disabled adult bloggers who attempt to intervene by suggesting privacy conventions such as writing anonymously, not sharing details about their child's difficult moments and offering tips to other parents in private (see Sequenzia, 2016).

Clearly, a minimal step required is that discussions of and practices of sharenting should move beyond a consideration of parent's motivations to establish boundaries around this mode of communication (Brosch, 2018, p. 78). Bosch points out, further, that a definition of sharenting must also consider the potential for a mass audience, the possibility of identifying the child and the ways these come together as a privacy violation. She offers a framework for establishing the "true level of sharenting and classifying parents" (Brosch, 2018, p. 80) that takes into account "the amount, frequency, content of posted information and the audience" (Brosch, 2018, p. 79). In Livingstone and Blum-Ross's (2020) example, the attention of a mass audience prompted that mother to radically rethink her privacy stewardship to the extent that she helped her daughter construct her own blog, to speak for herself. Drawing on Cynthia Lewiecki-Wilson (2003), Livingstone and Blum-Ross (2020) describe this as a process of co-constructing language. However, returning to The Mighty controversy with which we began this discussion, that mother too had claimed to co-construct the article with her son, yet it could not be described as giving him voice. The key issue for disability activists was the way disability was leveraged to attract a larger audience. In order to provide peer support for parents of children with disabilities, The Mighty reinforced "well-worn negative tropes, clichés, and stereotypes about disability" (Bad Cripple, 2016).

In a parallel to critiques of sharenting in online communities, adult disability activists criticise the focus on memoirs published by parents (Jack, 2014; Sousa, 2011). For disability activist Emily Ladau (2016) these and other media directed towards supporting parents of chil- dren with disability while usually well intentioned can become problematic if parents do not "relinquish their positions of authority and move to the role of advocateallies, advocating alongside, instead of on behalf of, disabled people" (Ladau, 2016) as their children age. Admittedly a fraught relationship, there is evidence too that strong relationships with parents of children with disability can be an important and strategic alliance for disability activists (Carey, Block, \& Scotch, 2020).

\section{Reflections on Data, Privacy, and Digital Futures for Children with Disabilities}

In this article, we have sought to identify and lay out some of the issues in approaching and framing concerns of data and privacy for children in disabilities. One stumbling block to advancing research and understanding in this area is that critical disability approaches and concepts still need to be better understood in the fields of media and communication. However, there is clearly an opportunity, as we have endeavoured to suggest, to think critically and creatively about disability and privacy in the lives of children as they rely upon digital technologies.

To convey a sense of the issues and stakes at play, we focussed on one leading example: that of sharenting in social media. It is a useful and illustrative example because it lays bare some of the practices, power relations, and deeply held views that frame privacy, personal information, and data of children with disabilities. As we note, the boundary turbulence occurring throughout these examples is not so much between the parent and child but between two discrete communities: adults with disabilities and special needs parents. These groups have much in common but digress on key issues related to the online privacy of children with disabilities. Tama Leaver (in press) observes a continuum of approaches parents take to the sharing of their children's images online. At one end of the continuum, parents trade privacy for commercial success while at the other parents take a more privacy-centred approach. In the tensions that constitute this field, children with disabilities do not get much of a "look in," when it comes to articulating, in their own ways, via their own social and digital practices, what they think and feel about privacy.

This is all the more a pity, given it is a zone where good intentions concerning children with disabilities abound. Accordingly, if we can disentangle and constructively address the issues involved, this can be a productive point for understanding the fundamental underpinnings and values, as we tackle the issues raised by the infrastructures, technology companies, and providers that shape much of the environment in which social media communities, interaction, moderation, norms, and rules are constituted and contested, and build diverse coalitions and alliances of stakeholders around these. In addition to these overt privacy violations from parents, children with disability are also subject to more intense regimes of digital surveillance and the subse- 
quent privacy issues that arise from having to use certain types of devices, wearables or even the many issues concerning surveillance, privacy, and data in relation to voice interfaces via Google, Facebook, or Amazon speakers. So, the agenda is wide and deep indeed.

To close on a positive note, there is good reasons to suggest that children with disabilities' evolving digital use practices themselves represents an opportunity for inclusion in conceptualization and debates concerning privacy-especially in relation to imagining and enacting good data frameworks and practices (Cranmer, 2020). This is an important area for future research, bringing together scattered work that does exist. Crucially, in research as well as policy and practice, the hallmark of genuine conceptual and social advance will be efforts that feature and are driven by children themselves reimagining good data futures for privacy-respecting disabled childhoods.

\section{Acknowledgments}

Our thanks to Rosemary Curtis for her proofreading this article.

\section{Conflict of Interests}

The authors declare no conflict of interests.

\section{References}

Abidin, C. (2017). \#Familygoals: Family influencers, calibrated amateurism, and justifying young digital labor. Social Media + Society, 3(2). https://doi.org/ $10.1177 / 2056305117707191$

Abidin, C. (2018). Internet celebrity: Understanding fame online. Bingley: Emerald.

Ajodhia-Andrew, A. (2016). Voices and visions from ethnoculturally diverse young people with disabilities. Rotterdam: Sense.

Alper, M. (2014). Digital youth with disabilities. Cambridge, MA: MIT Press.

Alper, M. (2015). Augmentative, alternative, and assistive: Reimagining the history of mobile computing and disability. IEEE Annals of the History of Computing, 37(1), 93-96. https://doi.org/10.1109/MAHC. 2015.3

Alper, M. (2017). Giving voice: Mobile communication, disability, and inequality. Cambridge, MA: MIT Press.

Alper, M., \& Goggin, G. (2017). Digital technology and rights in the lives of children with disabilities. New Media \& Society, 19(5), 726-740.

Ammari, T., Morris, M. R., \& Schoenebeck, S. Y. (2014). Accessing social support and overcoming judgment on Social Media among parents of children with special needs. In E. Adar \& P. Resnick (Eds.), Proceedings of the Eighth International AAAl Conference on Weblogs and Social Media (pp. 1-10). Palo Alto, CA: Association for the Advancement of Artificial Intelli- gence. Retrieved from https://www.microsoft.com/ en-us/research/wp-content/uploads/2016/02/ ammari_ICWSM2014.pdf

Bad Cripple. (2016). Cripping the mighty. Bad Cripple. Retrieved from http://badcripple.blogspot.com.au/ 2016/01/cripping-mighty.html

Bartholomew, M. K., Schoppe-Sullivan, S. J., Glassman, M., Kamp Dush, C. M., \& Sullivan, J. M. (2012). New parents' Facebook use at the transition to parenthood. Family Relations, 61(3), 455-469. https://doi. org/10.1111/j.1741-3729.2012.00708.x

Beckett, A. E., \& Campbell, T. (2015). The social model of disability as an oppositional device. Disability \& Society, 30(2), 270-283. https://doi.org/10.1080/ 09687599.2014 .999912

Benjamin-Thomas, T. E., Laliberte Rudman, D., GunaseeIan, J., Abraham, V. J., Cameron, D., McGrath, C., \& Vinoth Kumar, S. P. (2019). A participatory filmmaking process with children with disabilities in rural India: Working towards inclusive research. Methodological Innovations, 12(3). https://doi.org/10.1177/ 2059799119890795

Borgos-Rodriguez, K., Ringland, K. E., \& Piper, A. M. (2019). MyAutsomeFamilyLife: Analyzing parents of children with developmental disabilities on YouTube. Proceedings of the ACM on Human-Computer Interaction, 3, 1-26. https://doi.org/10.1145/3371885

Brosch, A. (2018). Sharenting: Why do parents violate their children's privacy? The New Educational Review, 54(4), 75-85. https://doi.org/10.15804/tner. 2018.54.4.06

Campbell, F. K. (2009). Contours of ableism: The production of disability and abledness. New York: Palgrave Macmillan.

Carey, A. C., Block, P., \& Scotch, R. K. (2020). Allies and obstacles: Disability activism and parents of children with disabilities. Philadelphia, PA: Temple University Press.

Convention on the Rights of Persons with Disabilities, 2006.

Convention on the Rights of the Child, 1989.

Couldry, N. (2010). Why voice matters? Culture and politics after neoliberalism. Los Angeles, CA: Sage.

Couldry, N., \& Mejias, U. A. (2019). The costs of connection: How data is colonizing human life and appropriating it for capitalism. Stanford, CA: Stanford University Press.

Counsel, J. (2019). What is sharenting? My Aspie World. Retrieved from https://myaspieworld.home. blog/sharenting

Cranmer, S. (2020). Disabled children's evolving digital use practices to support formal learning: A missed opportunity for inclusion. British Journal of Educational Technology, 51(2), 315-330. https://doi.org/ 10.1111/bjet.12827

Ellcessor, E., \& Kirkpatrick, B. (Eds.). (2017). Disability media studies. New York, NY: New York University Press. 
Ellis, K. (2015). Disability and popular culture: Focusing passion, creating community and expressing defiance. Surrey: Ashgate.

Ellis, K., Goggin, G., Haller, B., \& Curtis, R. (Eds.). (2020). Routledge companion to disability and media. New York, NY: Routledge.

Ellis, K., Goggin, G., \& Kent, M. (in press). Disability, children, and the invention of digital media. In L. Green et al. (Eds.), The Routledge companion of children and digital media. New York, NY: Routledge.

Eysenbach, G., Stendal, K., Petrič, G., Amann, J., \& Rubinelli, S. (2017). Views of community managers on knowledge co-creation in online communities for people with disabilities: Qualitative study. Journal of Medical Internet Research, 19(10). https://doi.org/ 10.2196/jmir.7406

Foley, K. R., Blackmore, A. M., Girdler, S., O'Donnell, M., Glauert, R., Llewellyn, G., \& Leonard, H. (2012). To feel belonged: The voices of children and youth with disabilities on the meaning of wellbeing. Child Indicators Research, 5(2), 375-319. https://doi.org/ 10.1007/s12187-011-9134-2

Garland-Thomson, R. (2017). Eugenic world building and disability: The strange world of Kazuo Ishiguro's Never Let Me Go. Journal of Medical Humanities, 38(2), 133-145. https://doi.org/10.1007/s10912015-9368-y

Gibson, C. (2016, January 5). A disability-focused website ran a 'funny' post on autism: Anger ensued. The Washington Post. Retrieved from https://bit.ly/ 3cuHFpw

Goggin, G. (2009). Disability and the ethics of listening. Continuum, 23(4), 489-502. https://doi.org/ $10.1080 / 10304310903012636$

Goodley, D., Lawthom, R., Liddiard, K., \& Runswick-Cole, K. (2019). Provocations for critical disability studies. Disability \& Society, 34(6), 972-997. https://doi.org/ 10.1080/09687599.2019.1566889

Griffo, M. (2015, December 22). Editor's note: Why we removed a story. The Mighty. https://themighty. com/2015/12/editors-note-why-we-removed-astory

Hadley, B. (2014). Disability, public space performance and spectatorship: Unconscious performers. Houndsmill: Palgrave Macmillan.

Harris, J. E. (2020). The privacy problem in disability antidiscrimination law. In A. Silvers, C. Shachar, I. G. Cohen, \& M. A. Stein (Eds.), Disability, health, law, and bioethics (pp. 159-170). Cambridge: Cambridge University Press.

Hays, A., \& Butauski, M. (2018). Privacy, disability, and family: Exploring the privacy management behaviors of parents with a child with autism. Western Journal of Communication, 82(3), 376-391. https://doi.org/ 10.1080/10570314.2017.1398834

Hevey, D. (1992). The creatures time forgot: Photography and disability imagery. London: Routledge.

larskaia-Smirnova, E. (2020). “It's no longer taboo, is it?"
Stories of intimate citizenship of people with disabilities in today's Russian public sphere. Sexuality \& Culture, 24(2), 428-446. https://doi.org/10.1007/ s12119-019-09699-z

Jack, J. (2014). Autism and gender: From refrigerator mothers to computer geeks. Champaign, IL: University of Illinois Press.

Jordan, A., \& Prendella, K. (2019). The invisible children of media research. Journal of Children and Media, 13(2), 235-240.

Kamenetz, A. (2019, June 5). The problem with 'sharenting.' The New York Times. Retrieved from https://www.nytimes.com/2019/06/05/opinion/ children-internet-privacy.html

Kopecky, K., Szotkowski, R., Aznar-Díaz, I., \& RomeroRodríguez, J.-M. (2020). The phenomenon of sharenting and its risks in the online environment: Experiences from Czech Republic and Spain. Children and Youth Services Review, 110. https://doi.org/10.1016/ j.childyouth.2020.104812

Kumar, P., \& Schoenebeck, S. (2015). The modern day baby book: Enacting good mothering and stewarding privacy on Facebook. In D. Cosley \& A. Forte (Eds.), CSCW '15: Proceedings of the 18th ACM Conference on Computer Supported Cooperative Work \& Social Computing (pp. 1302-1312). New York, NY: ACM. https://doi.org/10.1145/2675133.2675149

Ladau, E. (2016, January 13). The mighty question: Who should speak for the disability community? Words I Wheel By. Retrieved from https://wordsiwheelby. com/2016/01/the-mighty-question

Lansdown, G. (2014). Children with disabilities. In M. Sabatello \& M. Schulze (Eds.), Human rights and disability advocacy (pp. 97-112). Philadelphia, PA: University of Pennsylvania Press.

Lazar, J., \& Stein, M. A. (Eds.). (2017). Disability, human rights, and information technology. Philadelphia, PA: University of Pennsylvania Press.

Leaver, T. (in press). Balancing privacy: Sharenting, intimate surveillance and the right to be forgotten. In $\mathrm{L}$. Green, D. Holloway, K. Stevenson, T. Leaver, \& L. Haddon (Eds.), The Routledge companion to digital media and children. London: Routledge.

Lewiecki-Wilson, C. (2003). Rethinking rhetoric through mental disabilities. Rhetoric Review, 22(2), 156-167. Retrieved from https://www.jstor.org/stable/ 3093036

Liddiard, K., Runswick-Cole, K., Goodley, D., Whitney, S., Vogelmann, E., \& Watts, L. (2019). "I was excited by the idea of a project that focuses on those unasked questions": Co-producing disability research with disabled young people. Children \& Society, 33(2), 154-167.

Livingstone, S., \& Blum-Ross, A. (2020). Parenting for a digital future: How hopes and fears about technology shape children's lives. New York, NY: Oxford University Press.

Livingstone, S., \& Third, A. (2017). Children and young 
people's rights in the digital age: An emerging agenda. New Media \& Society, 19(5), 657-670.

Logsdon-Breakstone, S. (2015). Run down of \#CrippingTheMighty. Cracked Mirror in Shalott. Retrieved from https://crackedmirrorinshalott.wordpress. com/2015/12/23/run-down-of-crippingthemighty

Longmore, P. K. (2005). The cultural framing of disability: Telethons as a case study. PMLA, 120(2), 502-508. Retrieved from https://www.jstor.org/ stable/25486174

Maia, R. (2014). Recognition and the media. Houndsmill: Palgrave Macmillan.

McRae, L., Ellis, K., Kent, M., \& Locke, K. (2020). Privacy and the ethics of disability research: Changing perceptions of privacy and smartphone use. In J. Hunsinger, M. Allen, \& L. Klastrup (Eds), Second international handbook of internet research (pp. 413-429). Dordrecht: Springer. https://doi.org/ 10.1007/978-94-024-1555-1_66

Mitchell, D., \& Snyder, S. (2000). Narrative prosthesis: Disability and the dependencies of discourse. Ann Arbor, MI: University of Michigan Press.

Montague, M. (1993). Private lives? An initial investigation of privacy and disability issues: A discussion paper. Melbourne: Office of the Public Advocate, Privacy Commissioner, Human Rights Australia.

Nissenbaum, H. (2004). Privacy as contextual integrity. Washington Law Review, 79(1), 119-158. Retrieved from https://digitalcommons.law.uw.edu/cgi/ viewcontent.cgi?article $=4450 \&$ context $=w / r$

Nissenbaum, H. (2011). A contextual approach to privacy online. Daedalus, 140(4), 32-48.

Oliver, M. (2013). The social model of disability: Thirty years on. Disability \& Society, 28(7), 1-3).

Petronio, S. S. (2002). Boundaries of privacy: Dialectics of disclosure. Albany, NY: SUNY Press.

Price, M. (2011). Mad at school: Rhetorics of mental disability and academic life. Ann Arbor, MI: University of Michigan Press.

Priestley, M., \& Shah, S. (2011). Disability and social change: Private lives and public policies. Bristol: Policy Press.

Roulstone, A. (2016). Disability and technology: International and interdisciplinary perspectives. Basingstoke: Palgrave.

Runswick-Cole, K., Curran, T., \& Liddiard, K. (Eds.). (2018). Palgrave handbook of disabled childhood studies. London: Palgrave Macmillan.

Scheibling, C. (2020). "Real heroes care": How dad bloggers are reconstructing fatherhood and masculinities. Men and Masculinities, 23(1), 3-19. https://doi.org/ $10.1177 / 1097184 \times 18816506$

Schulze, M. (2010). Understanding the UN Convention on the Rights of Persons with Disabilities. New York, NY: Handicap International. Retrieved from http://www.handicap-international.fr/fileadmin/ documents/publications/HICRPDManual.pdf

Schweik, S. (2009). The ugly laws: Disability in public.
New York, NY: New York University Press.

Sequenzia, A. (2016). Privacy, and parental behaviour. Ollibean. Retrieved from https://ollibean.com/ privacy-and-parental-behavior

Shakespeare, T. (2018). Disability: The basic. London and New York, NY: Routledge.

Sinclair, J. (2012). Don't mourn for us. Autonomy, the Critical Journal of Interdisciplinary Autism Studies, 1(1). (Originally work published 1993). Retrieved from http://www.larry-arnold.net/Autonomy/index. php/autonomy/article/view/AR1

Sousa, A. C. (2011). From refrigerator mothers to warrior-heroes: The cultural identity transformation of mothers raising children with intellectual disabilities. Symbolic Interaction, 34(2), 220-243. https://doi.org/10.1525/si.2011.34.2.220

Third, A., Bellerose, D., Oliveira, J. D., Lala, G., \& Theakstone, G. (2017). Young and online: Children's perspectives on life in the digital age. (The state of the world's children 2017 companion report). Sydney: Western Sydney University. https://doi.org/10.4225/ 35/5a1b885f6d4db

Third, A., \& Collin, P. (2016). Rethinking (children's and young people's) citizenship through dialogues on digital practice. In A. McCosker, S. Vivienne, \& A. Johns (Eds.), Negotiating digital citizenship: Control, contest, and culture (pp. 41-59). London: Rowman \& Littlefield International.

Thompson, J. B. (2011). Shifting boundaries of public and private life. Theory, Culture, \& Society, 28(4), 49-70.

Tremain, S. (Ed.). (2015). Foucault and the government of disability. Ann Arbor, MI: University of Michigan Press.

Twomey, R. F. (2010). Employment law: Going beyond compliance to engagement and empowerment. Boston, MA: McGraw-Hill Irwin.

Whitburn, B., \& Plows, V. (Eds.). (2017). Inclusive education: Making sense of everyday practice. Rotterdam: Sense.

Whitehouse, A. (2018, April 27). Private: No access. Mother Pukka. Retrieved from https://www. motherpukka.co.uk/private-no-access

Woods, R., Milton, D., Arnold, L., \& Graby, S. (2018). Redefining critical autism studies: A more inclusive interpretation. Disability \& Society, 33(6), 974-979.

Yergeau, M. (2018). Authoring autism: On rhetoric and neurological queerness. Durham, NC: Duke University Press.

Young, S. (2012). We're not here for your inspiration. Ramp Up. Retrieved from www.abc.net.au/rampup/ articles/2012/07/02/3537035.htm

Zadrozny, B. (2019, May 21). Parents are poisoning their children with bleach to 'cure' autism: These moms are trying to stop it. $N B C$. Retrieved from https://www.nbcnews.com/tech/internet/momsgo-undercover-fight-fake-autism-cures-privatefacebook-groups-n1007871 
Zhang, D., \& Livingstone, S. (2019). Inequalities in how parents support their children's development with digital technologies: Parenting for a digital future (Survey Report No. 4). London: London School of
Economies, Department of Media and Communications. Retrieved from http://www.Ise.ac.uk/mediaand-communications/assets/documents/research/ preparing-for-a-digital-future/P4DF-Report-4.pdf

\section{About the Authors}

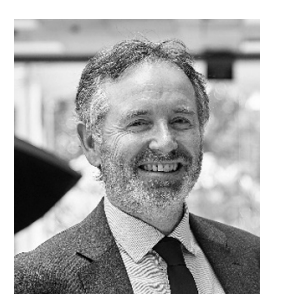

Gerard Goggin is Wee Kim Wee Professor of Communication Studies at Nanyang Technological University, Singapore. He is also Professor of Media and Communications, University of Sydney. His books on disability, media, technology, and culture include the co-authored Digital Disability (2003), Disability and the Media (2015), and the co-edited The Routledge Companion to Disability and Media (2020). Gerard is also widely published on mobile media and communication, with his most recent book being Apps: From Mobile Phones to Digital Lives (2021).

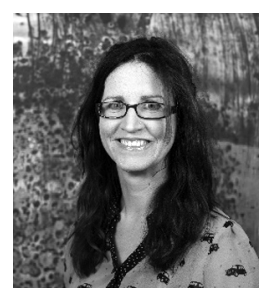

Katie Ellis (PhD) is the Director of the Centre for Culture and Technology at Curtin University, Australia, and an internationally recognised expert on disability and digital access. She is the Author or Editor of 17 books including most recently Disability and Digital Television Cultures and, with Gerard Goggin, Beth Haller, and Rosemary Curtis, The Routledge Companion to Disability and Media. 